\title{
5 Processing of German clauses
}

In this chapter, I review the literature about sentence processing in German. I will first discuss effects of argument ordering in the middle field (scrambling), mostly in V-final clauses. Subsequently, I will discuss effects of XP-fronting, i.e. moving one argument into the prefield of V2-clauses. The discussion of these two instances of argument dislocation in German will provide the baseline for the inspection of verb-related processing effects in Section 5.3. The gathered experimental findings indicate indicate that meaning-related information of the verb does not influences the processing of arguments in German but rather support the hypothesis that the full interpretation of the verb is delayed until the clause-final position.

\subsection{Scrambling}

Scrambling is a term for the reordering of constituents within the clausal domain (middle field), notably the extended VP (incl. vP and IP). It therefore contrasts with the placement of constituents into the clausal left periphery ( $w h$-movement, topicalization, fronting, etc.) and into the right periphery (extraposition).

First, I want to ensure that scrambling in German is an instance of displacement, comparable to filler-gap dependencies, which shows reactivation effects of the displaced element at the base position. For short scrambling Clahsen \& Featherston (1999) and Featherston (2001) report results from two cross-modal lexical priming studies which indicate that dislocated NPs are reactivated at their base position. In both structures, (1) and (2), the probe, which is identical to the dislocated element, received shorter reaction times at the gap site (\#2), in comparison to the control site (\#1). The shorter reaction times for the matching target indicate that the filler is reactivated at the gap site (\#2) which facilitates the lexical activation of the probe and reduces the reaction time in the lexical decision task ${ }^{1}$.

1 In a lexical decision task, participants have to decide whether a given string is an actual word or a non-word. For the here presented target items both, identical and unrelated, probes are actual words, the filler items contained also non-words. 
(1) a. Nach zwei Tagen Streit sprach der Richter [das Geschäft $]_{1}[\mathrm{dem}$ after two days dispute awarded the judge the business the ziemlich überraschten \#1 Andreas] \#2 $t_{1} \mathrm{zu}$.

rather surprised Andreas to

'After two days of dispute the judge awarded the business to the rather surprised Andreas.'

b. identical probe: Geschäft 'business', unrelated probe: Wagen 'car'

(Clahsen \& Featherston 1999: 426)

(2) [[So ein Haus $]_{1}$ [einer völlig normalen \#1 Kundin] \#2 $t_{1}$ verkaufen $]_{V P 2}$ Such a house a totally normal customer sell konnte nur Maria $t_{2}$. could only Maria

'Only Maria could sell such a house to a totally normal customer.'

- only identical probes, such as Haus 'house' - (Featherston 2001: 94)

In the following, I will look at the specific processing effects that arise from noncanonical argument ordering. For this, I divide the discussion into cases in which the arguments show unambiguous case marking, which allows immediate identification of non-canonical order, and cases with ambiguous case-marking, which gives rise to (temporary) ambiguities. We will see that the (lack of) unequivocal formal marking modulates the temporal locus of the experimental effects.

\subsubsection{Unambiguous case marking}

The linear order of arguments in the German middle field shows a linearization preference in which the subject is realized as the first argument. Subsequent arguments are preferably realized in the order dative (indirect object) before accusative (direct object) (see the linear precedence rules in Uszkoreit 1986). The validity of these linearization preferences have been empirically confirmed with reaction times and accuracy measures in comprehension and production studies, and in acceptability judgments (Bayer \& Marslen-Wilson 1992, Pechmann et al. 1996, Rösler et al. 1998, Röder et al. 2000, Bornkessel et al. 2002). On-line methods have revealed prolonged reading times on initial unambiguously case-marked objects (Scheepers 1997).

Several ERP studies investigated transitive (3) and ditransitive clauses (4) with scrambled, unambiguously case-marked arguments and provide robust evidence for the processing difficulties of non-canonical argument ordering. On the first argument position, initial dative or accusative objects result in a negativity which is located in fronto-central or anterior sites (Rösler et al. 1998, Bornkessel et 
al. 2002, 2003a, Schlesewsky et al. 2003, Bornkessel \& Schlesewsky 2006b). This negativity emerges shortly after the onset of the case-marked determiner (350400ms), and is absent for case marked pronouns (Schlesewsky et al. 2003). It is commonly interpreted as a reflection of an increased processing load (Bornkessel \& Schlesewsky 2006b) and, more specifically, as a reflection of working memory demands due to the storing of the argument for later integration (Rösler et al. 1998). On the second NP, non-canonical orders evoke a posterior positivity (300$400 \mathrm{~ms}$ ) which is detectable for DAT $\prec$ NOM order (Bornkessel et al. 2002, 2003b), and more pronounced for other non-canonical orders such as ACC $\prec$ NOM, DAT $\prec$ ACC, and ACC $\prec$ DAT (Rösler et al. 1998). Bornkessel et al. (2003b: 286-290) interpret this positivity as an indication of thematic reanalysis induced by a non-canonical argument order.

(3) a. NOM $\prec$ ACC

... dass der Jäger den Gärtner besucht. that [the hunter]Nom [the gardener]ACC visits

'...that the hunter visits the gardener.'

b. ACC $\prec$ NOM

... dass den Jäger der Gärtner besucht. that [the hunter]ACc [the gardener]NOM visit

'... that the gardener visits the hunter.'

c. $\mathrm{NOM}<\mathrm{DAT}$

... dass der Jäger dem Gärtner hilft. that [the hunter]Nom [the gardener]DAT helps

'... that the hunter helps the gardener.'

d. DAT $\prec$ NOM

... dass dem Jäger der Gärtner hilft. that [the hunter]DAT [the gardener] NOM helps

'... that the gardener helps the hunter.'

(Bornkessel et al. 2002: B24)

At the third argument position of ditransitive structures as in (4), Rösler et al. (1998) report a long-lasting posterior positivity and a fronto-central negativity (357-625ms) for the non-canonical order NOM $\prec$ ACC $<$ DAT (in contrast to NOM $<$ DAT $<$ ACC) on the determiner and the noun. At the clause-final verb, noncanonical orders lead to a posterior negativity (31-500ms) (Rösler et al. 1998: 166).

(4) Dann hat [der Vater] [dem Sohn] [den Schnuller] gegeben. then has [the father] NOM [the son]DAT [the pacifier]ACC given. 'Then the father gave the pacifier to the son.'

(Rösler et al. 1998: 153) 
I summarize that explicitly marked non-canonical argument order gives rise to immediate processing responses with initial negativities in response to the mismatch and later positivities indicating a reanalysis.

\subsubsection{Ambiguous case marking}

Many studies have investigated the processing of clauses with (partially) caseambiguous arguments. In German, only masculine singular nouns show morphologically distinct forms for nominative and accusative, as shown in Table 5.1.

Table 5.1: Case marking and syncretism in German

\begin{tabular}{|c|c|c|c|c|}
\hline & NominatiVe & ACCUSATIVE & Dative & Genitive \\
\hline MASCULINE DP & der/ein Mann & den/einen Mann & \multirow{2}{*}{$\begin{array}{l}\text { dem/einem Mann } \\
\text { dem/einem Ding }\end{array}$} & des/eines Mannes \\
\hline NEUTER DP & \multirow{2}{*}{\multicolumn{2}{|c|}{$\begin{array}{l}\text { das/ein Ding } \\
\text { die/eine Frau }\end{array}$}} & & des/eines Dinges \\
\hline FEMININE DP & & & \multicolumn{2}{|c|}{ der/einer Frau } \\
\hline proper name & \multicolumn{3}{|c|}{ Josef } & Josef's \\
\hline PLURAL DP & \multicolumn{2}{|c|}{ die Männer/Frauen/Dinge } & den Männern/Frauen/Dingen & der Männer/Frauen/Dinge \\
\hline bare PLURAL $(M, N)$ & \multicolumn{2}{|c|}{ Männer/Dinge } & Männern/Dingen & $\varnothing$ \\
\hline bare PLURAL (F) & \multicolumn{3}{|c|}{ Frauen } & $\varnothing$ \\
\hline
\end{tabular}

Due to this case syncretism, we can investigate the default parsing process by constructing initially ambiguous clauses that will be disambiguated at a later point. I noted that German shows a subject-first preference, which is indicated by processing difficulties for initial non-nominative arguments. Unsurprisingly, this preference prevails also with case-ambiguous arguments. If the first encountered argument is case-ambiguous, though compatible with nominative case, it will be initially interpreted as a subject. This subject-first preference is indicated by reanalysis processes that occur if the unambiguous nominative-marking of another argument, as in (5a), or the agreement on the verb, as in (5b), resolve the ambiguity towards a non-subject interpretation of the first argument. ${ }^{2}$ At the point of such a late disambiguation, a structural reanalysis has to take place. This is detectable by increased reaction times and decreased acceptability judgments (Bader \& Meng 1999, Scheepers et al. 2000, Bader \& Bayer 2006). Generally, disambiguation through the clause-final verb (agreement) is more severe than dis-

2 Bader \& Bayer (2006: 87-104) refer to these two types as nominal disambiguation and verbal disambiguation, respectively. 
ambiguation by arguments (Bader \& Bayer 2006: 103). In on-line measures, these reanalysis effects manifest in form of longer reading times for object-initial orders immediately at the disambiguating element (Bayer \& Marslen-Wilson 1992, Bader \& Lasser 1994, Scheepers et al. 2000, Kretzschmar et al. 2012). Similarly, in ERP experiments, such effects turn up immediately at the disambiguating region as well. In an initially ambiguous object-initial clause, a P600 (Friederici et al. 2001), an N400 (Schlesewsky \& Bornkessel 2004: 1217), and both (Mecklinger et al. 1995) are reported at the disambiguating clause-final verb. The effects are interpreted as the reflection of a reanalysis process. ${ }^{3}$
a. ... dass die Mutter
der Schüler angeschrien hat. that [the mother]Nom/ACC [the pupil]NOM shouted at has.3sG
'... that the pupil shouted at the mother.'
b. ...dassdie Mutter die Schüler angeschrienhaben. that [the mother]NOM/ACC [thepupils]NOM/ACC shouted at have.3PL '... that the pupils have shouted at the mother.'

In sum, we observe immediate local responses that correspond to reanalysis processes during the parsing of non-canonical argument orders. These effects either turn up at the point of disambiguation or at the unambiguously case-marked, non-initial arguments. In unambiguous cases, the reanalysis is preceded by an increased processing load at the first argument. Such mismatch or memory stacking effects are logically absent in ambiguous clauses.

\subsection{XP-fronting}

In addition to scrambling, German exhibits a second kind of argument reordering, to which I will refer here as XP-fronting. In contrast to scrambling, the leftward moved constituent targets a clause peripheral position, i.e. a specifier position in the C-domain. This position may be typically occupied by (topicalized) DPs, wh-elements, or adverbs but, as has been discussed in Chapter 2, basically every phrasal constituent may occupy this position. The location of this position is indicated by the two following observations: In V2-(main) clauses, the fronted element obligatorily precedes the finite verb and in embedded clauses it obligatorily precedes the subject. This position also marks an important contrast to scrambling. Following our assumptions above, the Spec-CP position is a position that

3 For arguments in favor of an interpretation of the N400 component as reanalysis, see Schlesewsky \& Bornkessel (2004: 1218, fn. 2). 
is usually filled through movement. ${ }^{4}$ Hence, the processor may immediately start the filler-gap parsing by encountering this position. There is simply no possibility for assuming that the fronted element is in its base position. I will restrict the discussion to cases of argument fronting. Clearly, the specifics of (un)ambiguous case marking of DPs in the prefield are identical to those of the scrambled DPs discussed in Section 5.1 above, see especially Table 5.1. As in the preceding section, I will first discuss cases of unambiguous marked arguments before I will examine cases with an ambiguous initial argument.

\subsubsection{Unambiguous case marking}

Sentences with object-before-subject order show longer reaction times and lower acceptability judgments than sentences with canonical subject-before-object order (Hemforth 1993: 157-170). In on-line measures with simple transitive sentences, as in (6), the following effects are reported: Object-initial orders evoke longer reading/reaction times on the first DP, the verb, and the second DP (Bayer \& Marslen-Wilson 1992, Hemforth 1993: 157-170, Konieczny 1996, Fanselow et al. 1999, Weskott 2003). Scheepers (1997: 147-160) notes that the effect on reading times for unambiguously accusative-marked initial DPs is larger in scrambling contexts than for XP-fronting.

(6) a. Der kluge Onkel besuchte den kleinen Jungen. [the smart uncle]NOM visits [the small boy]ACC 'The smart uncle visits the small boy.'

b. Den klugen Onkel besuchte der kleine Junge. [the smart uncle]ACc visits [the small boy]NOM 'The small boy visits the smart uncle.'

(Hemforth 1993: 158)

In ERP, sentences with non-canonical word order and unambiguously casemarked arguments show a lasting left anterior negativity (LAN) starting from the first dislocated element until the end of the second noun phrase (Matzke et al. 2002, Felser et al. 2003). This negativity is interpreted as an increased working memory demand caused by holding material in working memory for delayed integration. Matzke et al. (2002) report an additional N400 at frontotemporal sites on the second DP. Felser et al. (2003) report a similar early frontal negativity on the clause-final verb. The interpretation of this negativity remains inconclusive.

4 The only unequivocal exception in which Spec-CP is filled by an element lacking a base position, is the case of expletives, see Section 2.1.4.4. 
In sum, unambiguously case marked object-initial clauses show long-lasting processing difficulties that last until the base position of the fronted element. This is reflected by increased reading times and LAN-effects.

\subsubsection{Ambiguous case marking}

Similar to the scrambling cases above, the processor shows a preference for analyzing case-ambiguous fronted XPs, such as in (7), as subjects by default. This subject-first preference is evident in prolonged reaction times and lowered acceptability judgments for non-canonical orders (Bader \& Bayer 2006). Analogously, in on-line measures, prolonged reading times are found immediately at the disambiguating element in declarative clauses (Bayer \& Marslen-Wilson 1992, Hemforth 1993), wh-interrogatives (Schlesewsky et al. 2000), and relative clauses (Schriefers et al. 1995). In ERP studies with ambiguous intial arguments, the following effects were found: At the disambiguating second argument the non-canonical order evoked a frontotemporal N400 and a posterior positivity (Matzke et al. 2002, Bornkessel 2002, Frisch et al. 2002, Mecklinger et al. 1995)5.

(7) a. Die kluge Tante besuchte den kleinen Jungen. [the smart aunt]NOM/ACC visits [the small boy]ACC 'The smart aunt visits the small boy.'

b. Die kluge Tante besuchte der kleine Junge. [the smart aunt]NOM/ACC visits [the small boy]NOM 'The small boy visits the smart aunt.'

(Hemforth 1993: 158)

The subject-first preference is not restricted to German but has also been detected in other languages, such as Dutch (Kaan 1997) and Basque (Erdocia et al. 2009). Moreover, Weskott (2003) shows that this preference can be mitigated by increasing the inferability of the fronted object from the context and that the effect can even be canceled through syntactic priming of an object-before-subject structure.

In sum, I conclude that XP-fronting results in long-lasting processing demands which indicate a restructuring process that needs to hold the displaced element (filler) active in memory until the reconstruction site (gap). This is reflected by prolonged reading times and a LAN effect in ERPs. Scrambling, on the

5 The topography of the negativity reported in Mecklinger et al. (1995) is different: right lateralized, posterior. However, Mecklinger et al. (1995) used material in which the syntactically disambiguating auxiliary was preceded by a semantic disambiguation caused by the lexical meaning of the participle, which induced the N400. 
other hand, is more local. The reordered constituents never left the head domain, i. e. the extended VP. Therefore, no heavy restructuring has to take place but only local reranking/reordering. In case of local ambiguities, however, the results of both structures are almost identical. This is not surprising if we consider the process in detail. After encountering an ambiguous prefield argument, the processor will reconstruct it immediately into the highest VP internal position, i. e. the subject position. After this operation, all subsequent reanalysis processes are identical to scrambled orders in the middle field.

\subsection{The processing influence of the verb}

Processing effects of verb movement are considerably understudied. Evidence for the processing impact of verbs is mostly indirect and falls in two main classes: first, the interaction of the verb position with effects of argument processing and second, the influence of verb position on more general sentence processing routines, such as attachment and scope computation. In the last subsection, I will review the few direct investigations of processing verbs in sentences.

\subsubsection{Thematic processing}

The most direct role that the verb may play in on-line processing is the assignment of thematic roles to its arguments, thereby predicting the number and type of arguments and integrating these based on the verb frame. Hence, German V2-clauses could contrast quite sharply with their V-final counterparts because, in the former, the verb information may be early available for incremental processing. In the latter, the verbal elements follow all of the arguments. Hence, the verb frame cannot be accessible during the processing of the arguments. In this respect, experiencer object verbs, such as verblüffen 'baffle', constitute useful test cases because they have shown to exhibit an argument ordering that deviates from agentive verbs, such as zerreißen 'ripp up'. Experiencers are preferred to be linearized as the first argument, although they show the same case marking as objects of canonical agentive verbs, i. e. accusative or dative. ${ }^{6}$ In contrast to the subject-first preference, these verbs are said to exhibit an experiencer-first preference (see Verhoeven

6 Whether the argument order for experiencer object verbs really show a inherent preference for object-initial ordering is still a matter of current research. At least we can state that the subjectfirst preference for these verbs is significantly weaker than for agentive verbs (see Temme \& Verhoeven 2016 and references therein). 
2015, Temme \& Verhoeven 2016). Building on the reliable effect of non-canonical word order (scrambling) reported in Section 5.1, Schlesewsky \& Bornkessel (2004) discuss the influence of verb specific information on argument ordering. In sentences, as in (8), they contrast agentive verbs (folgen 'follow'/drohen 'threaten'), which show an unmarked subject-before-object order (8a), with experiencer object verbs (gefallen 'please'), which have an unmarked object-before-subject order (8b). At the clause-final verb, they report higher processing costs (early parietal positivity) for experiencer object verbs, which is detectable with both argument orders subject-before-object, and object-before-subject. Schlesewsky \& Bornkessel (2004) conclude that at the clause-final verb, the exceptional thematic hierarchy of experiencer object verbs induces a revision process.

a. ... dass der Mönch dem Bischof folgt/gefällt, obwohl ... that [the monk].NOM [the bishop].DAT follows/appeals, although

'... that the monk follows/is appealing to the bishop.'

b. ... dass dem Mönch der Bischof folgt/gefällt, obwohl ... that [the monk].DAT [the bishop].Nom follows/appeals, although

'... that the bishop follows/is appealing to the monk.'

(Schlesewsky \& Bornkessel 2004: 1215)

Bornkessel (2002: 99-116) investigates the same argument order contrast for V2clauses in which the verb information is present in advance of the arguments, as in (9). Hence, under the assumption of incremental processing, we expect that the argument order and the verb classes will interact, i. e. that subject-before-object order is preferred after agentive verbs and object-before-subject order is preferred after experiencer object verbs.

(9) a. Vielleicht droht/gefällt der Bäcker dem Regisseur seit der perhaps threatens/pleases [the baker]NOM [the director]DAT since the Party.

party

b. Vielleicht droht/gefällt dem Bäcker der Regisseur seit der perhaps threatens/pleases [the baker]DAT [the director]NOM since the Party.

party

$\begin{array}{lll}\text { c. Vielleicht droht/gefällt } & \text { Stefan } & \text { dem/der } \\ \text { perhaps threatens/pleases } & \text { Stefan.NOM/ACC/DAT } & \text { the.DAT/the.NOM } \\ \text { Regisseur seit der Party. } & & \\ \text { director since the party } & \end{array}$

(Bornkessel 2002: 100) 
Bornkessel (2002) reports that there are no effects detectable at the verb. This means either, that the differences of the two verb classes are too small to detect, or that the two verb classes are not processed differently at this point. In the unambiguously case-marked conditions, the initial dative DP (9b) elicited a positivity in the 300-900 ms window in contrast to the nominative DP (9a). Crucially, this effect was present for both verb types, and showed only slight topographical variation with respect to the verb types. For the initially case-ambiguous clauses, the dative-before-nominative order elicited a robust N400 effect at the disambiguating NP2 for both verb types. Agentive verbs additionally showed a weak P600 effect for dative-before-nominative order which indicates that after disambiguation a reanalysis of the object-before-subject order is initiated. This reanalysis is absent for experiencer verbs. In sum, the experiment showed a robust nominative-first preference for both verb types. The results of the first experiment suggest that the thematic structure of experiencer verbs is exceptional. This is further supported by a thematic reanalyses process that was detected only for agentive verbs at the clause-final position. However, the results of the experiment do not indicate that the verb information guides the process of constructing a thematic hierarchy. Crucially, the results suggest that even though the verb information is available before the arguments are processed, the effects are identical to the verb-final structures with respect to the components as well as in their temporal occurrence. "Therefore, the mechanisms responsible for the establishment of thematic relations between arguments also appear to operate without drawing upon verb-specific information, even when this information is available" (Schlesewsky \& Bornkessel 2004: 1227).

In a similar way, Scheepers et al. (2000) ${ }^{7}$ investigated the influence of verbmediated thematic information on argument ordering. They contrasted experiencer subject verbs, such as fürchten 'frighten', with experiencer object verbs, such as ängstigen 'fear', in V2 and V-final clauses, as shown in (10). ${ }^{8}$ In both clause types, the NP1 die strenge Lehrerin 'the strict teacher' is case-ambiguous between nominative and accusative. In acceptability judgment studies, Scheepers et al. (2000) stated that the object-before-subject order gave rise to higher acceptability judgments for experiencer object verbs and that the acceptability could even be enlarged by using an inanimate subject. This indicates that experiencer object verbs have a stronger tendency for object-before-subject order than experiencer

7 The reported experiments are also published in Scheepers (1997: 123-146).

8 Scheepers et al. (2000) refer to experiencer subject verbs with with psychological statives and to experiencer object verbs with psychological causatives. 
subject verbs, which might be reflected in on-line measures as well. The predictions concerning (10) were tested in an eye tracking study.

a. V-final-S $\prec 0$ vs. $\mathrm{O} \prec \mathrm{S}$

Dass $\left.\right|_{\mathrm{NP} 1}$ die strenge Lehrerin $\left.\right|_{\mathrm{NP} 2}$ den stillen Schüler/ der stillen that the strict teacher [the quiet pupil]Acc/ [the quiet

Schüler $\left.\right|_{A D V}$ ein wenig $\left.\right|_{\text {Verb }}$ ängstigte/ fürchtete, | hatte der Psychologe pupil]Nom a bit fears/ frightens had the psychologist von einigen Klassenkameraden erfahren.

from some class mates get to know

'That the strict teacher frightened the quiet pupil a bit, the psycologist learned from some of the class mates' or

'That the quiet pupil feared the strict teacher a bit, ...'

b. V2-S $\prec \mathrm{O}$ vs. $\mathrm{O} \prec \mathrm{S}$

Offenbar $\left.\right|_{\text {Verb }}$ ängstigte/ fürchtete $\left.\right|_{\mathrm{NP} 1}$ die strenge Lehrerin $\left.\right|_{\mathrm{NP} 2}$ den obviously fears/ frightens the strict teacher [the stillen Schüler/ der stille Schüler $\left.\right|_{\mathrm{ADV}}$ ein wenig, | was der quiet pupil]ACC/ [the quiet pupil]NOM a bit what the Psychologe von einigen Klassenkameraden erfahren hatte. psychologist from some class mates get to know had 'Obviously the strict teacher frightened the quiet pupil a bit, ...' or 'Obviously the quiet pupil feared the strict teacher a bit, ...'

(Scheepers et al. 2000: 115-117)

In V2-clauses, experiencer subject verbs elicited longer reading times in early (first pass reading times) and late measures (regression path duration). Expectedly, no effect turned up at the case ambiguous NP1. In both clause types the object-beforesubject order evoke longer reading times in early measures (first path reading times) only on the disambiguating NP2. The late measures (regression path duration) revealed longer reading times for the object-before-subject order on the disambiguating NP2, the following adverb and the verb in V-final clauses. Additionally, the late measures also revealed an interaction of verb type and argument ordering on the clause-final element, i. e. the adverbial in V2-clauses and the verb in V-final clauses. This interaction points in the expected direction, namely that the preference for SO and the dispreference for OS is more pronounced in experiencer subject verbs. This late effect is still visible in the answer accuracy of the comprehension question which followed the items: Whereas no differences were detected within canonical subject-initial sentences, answer accuracy after objectinitial clauses were significantly lower only for the experiencer subject verbs, irrespective of the verb position (V2 vs. V-final). This indicates that the thematic information of the verb influences processing only at a late point during processing 
German clauses - in fact, so late that it spills over to subsequent tasks. That these effects turn up at the end of the clause also in V2-clauses is unexpected under an incremental processing hypothesis, but matches the V2-Reconstruction Hypothesis.

Scheepers (1997: 171-186) investigates the processing of thematic hierarchies by constrasting verbs that take a goal-PP, like werfen 'throw', with verbs that select a theme-PP, such as bewerfen 'pelt', as shown in (11). An acceptability pretest indicated that verbs which take theme-PPs show a stronger preference for an $\mathrm{NP}<\mathrm{PP}$ order in (11c), compared to verbs which take a goal-PP.

a. PP-goal-NP $\prec P P$

Der Junge warf denspitzen Stein gestern aufdie neue Garagentür, ... the boy threw the pointed stoneyesterday at the new garage door

b. PP-goal-PP $\prec \mathrm{NP}$

Der Junge warf auf die neue Garagentür gestern den spitzen the boy threw at the new garage door yesterday the pointed Stein, ...

stone

c. PP-theme-NP $\prec \mathrm{PP}$

Der Junge bewarf die neue Garagentür gestern mit dem spitzen the boy pelt the new garage door yesterday with the pointed Stein, ... stone

d. PP-theme-PP $\prec \mathrm{NP}$

Der Junge bewarf mit demspitzen Stein gestern die neue Garagentür, ... the boy pelt with the pointedstoneyesterday the new garage door

e. V-final scheme

Der Junge hat $[\mathrm{NP} / \mathrm{PP}] 1$ gestern $\quad[\mathrm{NP} / \mathrm{PP}] 2$ geworfen/beworfen, ... the boy has [NP/PP]1 yesterday [NP/PP]2 thrown/pelted

(Scheepers 1997: 172)

The self-paced reading experiment revealed a general $\mathrm{NP}<\mathrm{PP}$ preference (shorter reading times) on the first argument and the sentence-final spillover region. This preference was more pronounced for verbs with theme-PPs, which is in accordance with the acceptability judgments. However, the effects were independent of the verb position and therefore plausibly stem from properties of the arguments. No effects could be detected at the second argument. At the clause-final verb, Scheepers (1997) detected an interaction of argument order and verb type: Goal$\mathrm{PP}$ verbs (werfen) show shorter reading times after $\mathrm{PP}<\mathrm{NP}$ order whereas Theme$\mathrm{PP}$ verbs (bewerfen) show shorter reading times after $\mathrm{NP}<\mathrm{PP}$ order. Thus, process- 
ing advantages due to argument order which is consistent with the thematic frame of the verb are detectable only for clause-final verbs. The experiment did not indicate advantages during processing of the argument patterns matching the thematic frame, which could be accessible early on in V2-clauses.

To account for this asymmetry Scheepers (1997) and Scheepers et al. (2000) assume that syntactic and thematic processing are (perhaps modularly) separated, which has the consequence that information about the thematic roles (linking) is not available until the clause-final wrap-up process. In a similar way, Schlesewsky \& Bornkessel (2004) account for the above mentioned ERP results. They propose the argument dependency model (ADM), for which they assume two independent processing pathways: a syntactic pathway and a thematic pathway. Schlesewsky \& Bornkessel (2004) argue that unambiguous case marking and animacy information feed into the thematic pathway, while in case of morphological ambiguity, linear order feeds into the syntactic pathway. ${ }^{9}$ They conclude that both pathways operate independently of (potentially) available verb meaning. More explicitly, even if the lexical verb appears in the V2-position in German, there is no indication that the meaning of the verb influences the incremental interpretation process. The availability or operatibility of the two pathways is dependent on languagespecific parameters: If a language does not provide enough morphological case information, the syntactic pathway will most likely dominate (e.g. English). In sum, both accounts attribute the absence of verb-specific processing influences until the clause-final position to a modular separation of syntactic and thematic processing. The V2-Reconstruction Hypothesis provides a principled explanation for this separation which otherwise has to be stipulated.

\subsubsection{Attachment ambiguities}

Further evidence in support of the V2-Reconstruction Hypothesis comes from attachment ambiguities of PP-adjuncts that can either modify the VP or the preceding NP. Konieczny et al. (1997) investigate the role of the lexical verb on structural attachment of NPs and PPs in German. They constructed experimental sentences in which the PP is either attached low, i. e. internal (as daugther node) to the previously processed phrase, as in (12a), or high-attached, i. e. external to the previously processed phrase, as in (12b).

9 Several authors also have stressed that in absence of case marking thematic ranking can be guided by animacy (contrasts) of the arguments in German (MacWhinney et al. 1984, Schlesewsky \& Bornkessel 2004, Czypionka 2013). 
(12) $\quad[\mathrm{vP} N \mathrm{NP}+\mathrm{NP}+\mathrm{PP}]$

a.

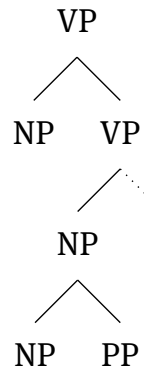

b.

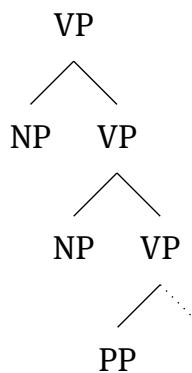

In a series of three eye-tracking studies, Konieczny et al. (1997) investigate the attachment strategy and the potential garden-path effect that may result from erroneous attachment in German. They contrast clauses with the lexical verb in V2position, as in (13a) and (13b), and clauses with the lexical verb in clause-final position, as in (13c) and (13d). Evidently, if the lexical verb occurs in clause-final position, it cannot aid the parser in resolving the attachment problem. However, if the lexical verb precedes the arguments, the parser may be biased towards high or low attachment. Konieczny et al. (1997) tested two different verb classes, one class with a strong preference for PP-adjuncts, such as beobachten 'watch', and one class without a preference, such as erblicken 'catch sight of', to amplify the impact of the verb.

a. V2-VP-biased PP

Marion beobachtete [das Pferd] [mit dem neuen Fernglas].

Marion watched the horse with the new binoculars

'Marion watched the horse with the new binoculars.'

b. V2-NP-biased PP

Marion beobachtete [das Pferd mit dem weißen Fleck].

Marion watched the horse with the white patch

'Marion watched the horse with the white patch'

c. V-final-VP-biased PP

Ich habe gehört, dass Marion [das Pferd] [mit dem neuen Fernglas]

I have heard that Marion the horse with the new binoculars beobachtete.

watched

'I have heard that Marion watched the horse with the new binoculars.' 
d. V-final-NP-biased PP

Ich habe gehört, dass Marion [das Pferd mit dem weißen Fleck] I have heard that Marion the horse with the white patch beobachtete.

watched

'I have heard that Marion watched the horse with the white patch.'

(cf. Konieczny et al. 1997: 317)

The results show essentially three effects: First, in V-final clauses, reading time measures are shorter for NP-biased PPs (with the white patch), which indicates that low attachment to the immediately preceding phrase seems to be the default. Second, in the V2 condition, on the other hand, reading times for VP-biased PPs (with the new binoculars) were shorter than for NP-biased PPs. Third, reading times on the PP-segment are longer in V2-clauses than in V-final clauses (Konieczny et al. 1997, Konieczny \& Völker 2000). The first effect is straightforward: In V-final clauses, the parser adheres to the principle of Minimal Attachment ${ }^{10}$ and initially attaches the PP to the last active node, i. e. the object NP. ${ }^{11}$ After the attachment, the phrase will be interpreted. In case of a VP-biased PP (13c) the structure has to be reanalyzed such that the PP will be high-attached to the VP. This reanalysis is visible as prolonged reading times. What is the difference in V2-clauses? After encountering the object NP das Pferd 'the horse' the verb is reconstructed into the final position and the clause is complete for interpretation, as illustrated in (14a). In contrast to the V-final counterpart, the NP-node is already closed, because the structure is well-formed for interpretation. Now, when the parser encounters a PP, it adheres to late closure and tries to integrate this PP into the current clause. But it will do so in accordance with minimal attachment, i. e. with the structurally most parsimonious operation, i. e. high attachment to the VP, as shown in (14b). If this is the correct structure, as in (13a), the processing is complete. In case the high attachment is semantically ill-formed, as in (13b), the structure has to be revised again, as illustrated in (14c). This account perfectly explains the effect of the PPattachment experiments. The V-final attachment strategy is the default strategy that prefers low attachment. Reading times on the PP are longer in V2-clauses because in these configurations the structure that is already pushed to interpretation has to be reopened to include the PP. Furthermore, low attachment in V2-clauses involves an additional repair process which results in even longer reading times.

10 See Section 4.2.1

11 In contrast to Konieczny et al. (1997), I assume that a VP is postulated in a top down fashion. In V-final clauses, the V-head of this VP, however, is not or at least less active than the NP node because it has not been encountered yet. 
(14)

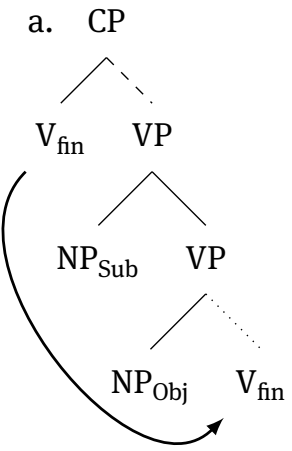

b. $\mathrm{CP}$

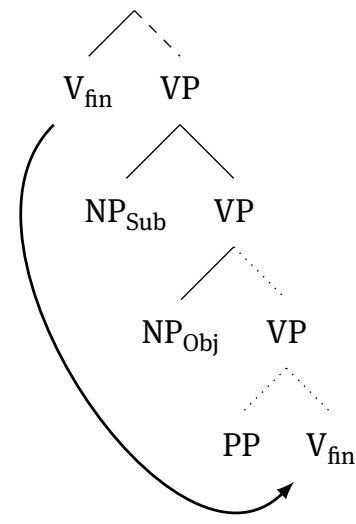

c. $\mathrm{CP}$

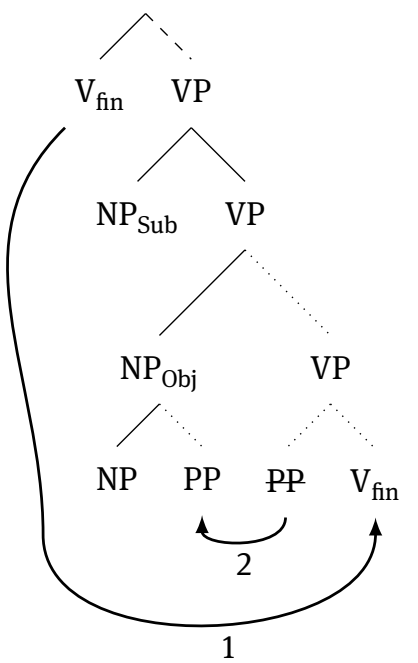

Konieczny et al. (1997) provide a different interpretation of the results in a headdriven approach. They assume that phrases are only postulated if a head has been encountered. As a consequence, the PP is not attached to the VP in V-final clauses because the VP is not postulated until the final verb is reached. In V2-clauses the encounter of the finite verb leads to a postulation of a VP. The account of Konieczny et al. (1997) relies on the lexical subcategorization information. Hence, they must assume that the verb in the V2-position must be interpreted. An assumption that is unwarranted, as I have already argued and as will become more evident in the following.

\subsubsection{Scope computing}

Bott \& Schlotterbeck (2015) investigate scope computation in German, more specifically the reconstruction of object quantifiers. As shown in (15), all their experimental sentences involved accusative-marked objects in clause-initial position. The accusative object has to be reconstructed. The unmarked base position of the object is located directly after the nominative subject and before the adverbial. The displaced object always contains a quantifier jeden 'each'. In (15a) the displaced object additionally contains a possesive pronoun seiner 'his' which is bound by the quantified subject genau ein Lehrer 'exactly one teacher'. This relation, in which the subject must take scope over the object, ensures the reconstruction of the object. Bott \& Schlotterbeck (2015) contrast an hypothesis of 
incremental scope computation, which will determine the relative scope as soon as the quantifying expressions are encountered, with the hypothesis of global interpretation, which assumes that the determination of relative scope requires also the interpretation of the predicate, i. e. scope is computed for (minimal) clauses. By placing the lexical verb either in second (15a-15d) or in clause-final position (15e), the predictions of the two hypotheses can be contrasted. Although both clause types in (15) are clearly main clauses with V2-order, i. e. the finite verb in second position, I will nevertheless follow Bott \& Schlotterbeck (2015) and call clauses with the lexical verb in second position V2 condition and clauses with the lexical verb in clause-final position $V$-final condition.

(15) a. QQ+BIND

Jeden seiner Schüler lobte genau ein Lehrer voller [Each.Q of his pupils]ACC praised [exactly.Q one teacher] NOM full of Wohlwollen. goodwill.

b. QQ-BIND

Jeden dieser Schüler lobte genau ein Lehrer voller [Each.Q of these pupils]ACC praised [exactly.Q one teacher]NOM full of Wohlwollen.

goodwill.

c. QDEF+BIND

Jeden seiner Schüler lobte der neue Lehrer voller [Each.Q of his pupils]ACC praised [the.DEF new teacher]NOM full of Wohlwollen.

goodwill.

d. QDEF-BIND

Jeden dieser Schüler lobte der neue Lehrer voller [Each.Q of these pupils]ACC praised [the.DEF new teacher]NOM full of Wohlwollen.

goodwill.

e. V-final scheme

Jeden ... Schüler hat ... Lehrer voller Wohlwollen gelobt.

[Each pupils]ACC has [ teacher] NOM full of goodwill praised.

(Bott \& Schlotterbeck 2015: 64-65)

For the self-paced reading study, Bott \& Schlotterbeck (2015) report a main effect with longer reading times for V2-clauses than for V-final clauses. The first spillover region voller 'full of' revealed a scope inversion effect only for V2-clauses, i. e. the condition in which the dislocated pronoun is bound by the subject (15a) elicited 
longer reading times only in the V2 condition. Additionally, at the clause-final region, a strong effect of DP-type turned up with longer reading times for the doubly quantified clauses (QQ). The effect seems to depend on the verb, because it does appear before the verb in the $\mathrm{V}$-final condition. This indicates that the second spillover region is also the point at which the verb receives its full interpretation in the V2 condition. Bott \& Schlotterbeck (2015) interpret this simply as a spillover effect. Under the V2-Reconstruction Hypothesis, however, this effect receives a principled explanation. After encountering the second argument, the processor invariably reconstructs the fronted object and the finite verb. In the V2 condition, the sentence is already complete and will be interpreted. In the V-final condition, however, the interpretation is delayed until the encounter of the clause-final verb.

For a parallel eye-tracking experiment, Bott \& Schlotterbeck (2015) report increased reading times in late measures (go-past times and first-pass regression ratios) for both the doubly quantified condition and scope inversion. Both main effects are detectable only at the clause-final element, irrespective of the position of the lexical verb. Additionally, Bott \& Schlotterbeck (2015) report longer secondpass times for the two arguments and the V2-position within the scope inversion condition. This indicates that in eye-tracking readers computed scope rather late, after reading the sentence.

In sum, the experiments on scope reconstruction revealed the same pattern as the processing of thematic structure. Processing effects that are dependent on the meaning of the verb show up at the end of the sentence, whether the verb is in $\mathrm{V} 2$ or in V-final position. This indicates that, in German, the interpretation of the verb is delayed until the base position of the verb (right edge of the VP).

\subsubsection{Processing of the verb: Anticipation and integration}

Now, I take a more direct look at the processing of the verb. Weyerts et al. (2002) report results from self-paced reading and ERP experiments which they interpret as providing evidence for the claim that German speakers process finite verbs in second position more easily than finite verbs in clause-final position. In light of the theoretical discussion above, these results seem quite surprising. A detailed inspection will show that these claims are unsubstantiated.

Weyerts et al. (2002) contrast coordinated matrix clauses with embedded clauses, as in (16).

(16) a. Hans facht das Lagerfeuer an, und Paul (öffnet) die Dosen (*öffnet). Hans fans the camp fire PART and Paul opens the cans opens 'Hans fans the camp fire and Paul opens the cans.' 
b. Die Leiterin des Kochkurses bestimmt, dass Erika 〈 ${ }^{\star}$ öfnet〉 die the director of the cookery course decides that Erika opens the Dosen 〈öffnet).

cans opens

'The director of the cookery course decides that Heather the cans opens.'

(Weyerts et al. 2002: 219)

For the self-paced reading experiment, they report longer reading times for the object-verb region only within the coordinated main clauses with ungrammatical V-final order. Weyerts et al. (2002) interpret the absence of an ungrammaticality effect for the embedded V2-clause condition as evidence for a general processing preference of early finite verbs. It is, however, very likely that the absence of prolonged reading times is caused by syntactic priming, because all target clauses follow a main clause with V2-order. Consequently, we would expect that processing V2-order in the second clause is facilitated even if it is ungrammatical, whereas no facilitation is provided for V-final clauses in coordinated main clauses. Syntactic priming (parallel processing) has been shown to reduce reading times (Frazier et al. 1984, Weskott 2003).

For the ERP experiments with similar stimuli, Weyerts et al. (2002) report an early anterior negativity in OV clauses in contrast to VO clauses, which they interpret as an increased processing load for verb-final structures. However, Schlesewsky et al. (2002) argue that this effect is, in fact, an early positivity that stems from the comparison of a noun, i.e. the object of the verb-final clause, with the verb in the VO-clause. Schlesewsky et al. (2002) note that such word class differences that match in topography and latency have been reported for studies in English. Similar results from ERP responses to a lexical decision task that contrast nouns and verbs in German are also reported by Pulvermüller et al. (1999). The critical reexamination additionally explains why, in the self-paced reading study, the word order interacted with ungrammaticality (syntactic priming) whereas the ERP responses were independent of the grammaticality (word class difference). In sum, despite the claim that finite verbs are easier to process in an early clause position, the discussion of Weyerts et al. (2002) does not shed any light on the actual processing of the finite verb in the German clause, i.e. when and in which depth the finite verb is interpreted and whether or how it influences processing of other clausal constituents. For example, under the V2-Reconstruction Hypothesis, it is assumed that the first encounter of the displaced verb only involves a shallow parse. Hence, we would predict faster processing in comparison to clause-final verbs, but obviously we do not want to compare these instances. The discussion of reanalysis effects above have proven that clause-final verbs trigger several pro- 
cessing routines that relate to the preceding argument structure. Hence, a simple comparison between the two positions is unjustified.

Furthermore, the claim that clause-final verbs are generally harder to process is at best an oversimplification. Precisely for German, it has been argued that processing load varies as a function of preverbal material. Konieczny (2000) reports results from a self-paced reading study that became known as the antilocality effect. In German verb-final clauses, reading times on the verb turned out to be shorter with increasing length of preverbal material. Konieczny (2000) takes this as an indication of a type reduction operation: The more elements precede the clause-final verb, the faster it will be processed. This effect is more pronounced for predictable elements, such as arguments, but also detectable for adjuncts (Konieczny 2000, Konieczny \& Döring 2003, Levy \& Keller 2013). The assumption of the anticipation hypothesis, as it was called later, is that the information of the arguments help to narrow down the verb to come and make it more expected. This essentially leads to the shorter processing time on the verb.

But are we bound to conclude that verbs in second position exhibit longer reading times than their clause-final correspondents, because they cannot be anticipated? On the contrary. Scheepers (1997) reports that verbs in V2-position are read faster than their corresponding counterparts in clause-final position. He attributes this to an opaque clause-final wrap-up process. Although I am not denying that clause-final wrap-up process may play a role here, I suggest that this effect may mask verb-specific processes. Under the assumption that the verb is not fully interpreted in the V2-position, it seems plausible that the processing time at this early point is rather short. A clause-final verb, on the other hand, can immediately integrate all its arguments and modifiers (except for complement clauses), and be immediately interpreted. Therefore processing of clause-final verbs is predicted to show longer processing time.

Finally, I present direct evidence for the fundamental assumption that verbal heads do reconstruct in a filler-gap-like fashion. Love \& Swinney (1998) cite a cross-modal lexical priming study by Basilico et al. (1995) ${ }^{12}$ that investigated reactivation priming effects for verbs in Spanish verb-initial structures, VSO and VOS. The rationale goes as follows: Spanish has a basic SVO structure. Both verbinitial orders are derived by fronting the pre-subject material, as shown in (17). Consequently we expect that the verb is reconstructed into a position between the subject and the object in the VSO structure in (17a), but not in the VOS structure in (17b).

12 Many thanks to Inés Antón-Méndez for rummaging up the paper and sharing it. 
(17) a. VSO

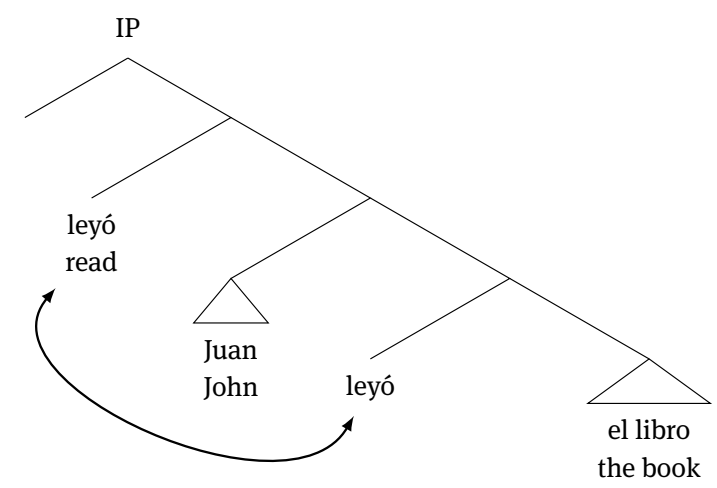

b. VOS

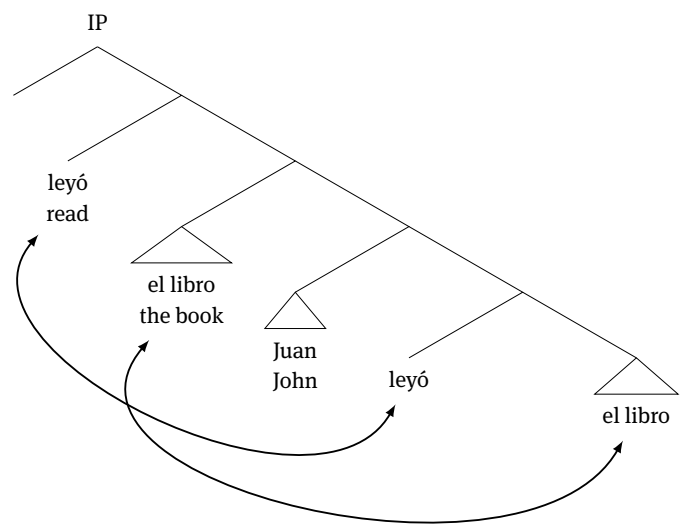

(18) a. VSO

Vieron $_{1}$ [tus vecinos, los de la casa rosa] \#\# $\mathrm{t}_{1}$ [a todos sus see your neighbors them from the house pink to all their hijos, hijas y nietos] [el fin de semana pasado]? sons daughters and grand children the end of week past 'Did your neighbors from the pink house see all their sons daughters and grand children last weekend?'

b. VOS

El fin de semana pasado vieron ${ }_{1}$ a todos sus hijos, hijas y [the end of week past] see [to all their sons daughters and nietos \#\# tus vecinos, los de la casa rosa $t_{1}$ ? grand children] [your neighbors them from the house pink] 'Last weekend, did you see all their sons daughters and grand children your neighbors from the pink house?' 
c. prime position: \#\#, related prime: mirar 'look', unrelated prime: lavar 'wash'

Basilico et al. (1995) report trace reactivation effects of the verb between the subject and the object position (\#\#) in VSO clauses in (18a) but none in the VOS structures in (18b). These results therefore provide positive evidence that also verbs, i. e. syntactic heads, may enter filler-gap dependencies in a similar way as it is widely accepted for dislocated phrasal constituents.

\subsection{Chapter summary}

In sum, the review of the experimental literature revealed that, clauses in which the lexical verb occurs in the V2-position do not reveal processing effects that are indicative of predictive parsing, although in German predicates show considerable variation with respect to number, case-marking, order, and syntactic category of the selected arguments. To the contrary, thematic effects are detectable at the clause-final position, irrespective of the surface position of the verb. Comparable temporal signatures are likewise found in experiments investigating scope reconstructions that require access to the verb meaning. The experimental results from attachment ambiguities also match the prediction that in V-final clauses, phrases remain open as attachment sites but in V2-clauses argument phrases are closed as early as possible. Additionally, I presented evidence from Spanish which indicates that verbs may enter filler-gap dependencies and hence support the view that they are reactivated at their base position. Taken together, the literature review provided empirical support for the V2-Reconstruction Hypothesis. 